\title{
0 renascimento do parto, e o que o SUS tem a ver com isso
}

The rebirth of delivery, and what the Brazilian National Health System has to do with this

\author{
El renacimiento del parto y el papel del Sistema Único de Salud en ello
}

O que faz com que um filme seja tão valorizado pelo seu público que este se encarregue coletivamente do seu financiamento, divulgação e distribuição? O documentário O renascimento do parto bateu o recorde de crowdfunding mais rápido no Brasil: a meta inicial, estimada para sessenta dias, foi alcançada em apenas três, garantindo sua edição final. Divulgado amplamente nas redes sociais desde antes do seu lançamento em agosto de 2013, em outubro já havia sido visto por mais de dez vezes o número médio de espectadores de documentários no Brasil. Nos municípios menores, usuárias organizam campanhas para que o filme chegue até elas. $\bigcirc$ uso do filme como recurso educativo certamente se multiplicará com seu lançamento no formato DVD, esperado para fevereiro de 2014.

O Renascimento vem numa sequencia de fenômenos de mídia produzidos pelos movimentos sociais que lutam por mudanças na assistência ao parto no Brasil. Como o vídeo do parto domiciliar de Sabrina Ferigato ${ }^{1}$, visto mais de quatro milhões de vezes, e que motivou desde muitas repercussões na imprensa, e até uma ameaça de processo contra o professor Jorge Kuhn (por ter declarado seu apoio ao parto domiciliar para pacientes selecionadas, prática prevista em vários países desenvolvidos). Esta ameaça, por sua vez, desencadeou dezenas de manifestações de rua em todo o Brasil em apoio ao professor, e ao direito de escolha, pela mulher, do profissional e do local de parto.
O filme mostra que as intervenções que a grande maioria dos profissionais entende como o cotidiano "normal" da assistência (episiotomias e ocitocina não informadas e não consentidas, imobilização deitada de costas com as pernas abertas, negação de acompanhantes e de privacidade, manobra de kristeller, hospitalização obrigatória, imposição da cesárea por motivos fictícios, entre outros), passam a ser descritas pelas usuárias como formas de violência contra as mulheres. Estas novas narrativas causam espanto nos profissionais, como mostra o filme "Violência obstétrica - a voz das brasileiras" 2 (melhor documentário no Seminário Internacional Fazendo Gênero, 2013), que denuncia em detalhes esta realidade, e que foi também feito coletivamente, a partir de uma pesquisa baseada na Internet, com as narrativas das mulheres feitas por elas mesmas, em suas casas².

Além de evidenciarem o vigor das novas estéticas, conhecimentos e projetos de saúde gestados coletivamente pelas redes sociais, estes filmes chamam a atenção para uma tendência nas relações médico-paciente nos próximos anos: pode acontecer de as usuárias conhecerem melhor as evidências científicas sobre segurança e efetividade das práticas de saúde que os profissionais. Com o advento da Internet, as usuárias e suas famílias conhecem a realidade de outros países, onde políticas públicas promovem o parto espontâneo e centrado na mulher. Entram em contato com a literatura científica e de direitos 
sobre o parto (em linguagem "livre de jargão", dirigida a usuárias), o que leva a um choque cultural frente às crenças dos profissionais de saúde. Ao se apropriarem da informação antes monopolizada pelo médico, as usuárias relativizam a autoridade do profissional, afirmam sua insatisfação com o que é oferecido, reinterpretam sua experiência, denunciam a violência a que se sentem submetidas, e reivindicam seu direito de escolha e recusa informada ${ }^{3}$.

O filme mostra que temos um discurso duplo, ambivalente, onde se afirma a superioridade dos desfechos do parto "normal", porém o discurso subjacente, baseado na tocofobia (medo, aversão, nojo do parto), é hegemônico e autoritativo - é o que vale na prática. Não há discurso oficial, no setor público ou privado, que consiga contradizer a realidade de que a grande maioria das profissionais de saúde, gestores e formuladores de políticas tem filhos por cesáreas. Como conta uma médica no filme: "Ficaram muito espantados, me disseram que há dez anos nenhuma médica tinha parto normal neste hospital".

Para muitos profissionais, parece haver algo de essencialmente errado nas mulheres quererem um parto normal, pois elas deveriam "desejar" uma cesárea. No filme, a obstetra Melânia Amorim afirma que, "quando se entrevistam mulheres no pós-parto, elas muitas vezes acreditam que houve uma indicação real de cesariana. Quando se entrevistam os médicos, eles vão atribuir a culpa da cesariana a uma decisão da mulher". Melânia e outros entrevistados listam dezenas de indicações de cesárea fictícias que são utilizadas para coagir as mulheres, com ameaças de desfechos adversos, para o bebê ou para elas, caso não obedeçam imediatamente.

Os profissionais por sua vez, ainda se apegam a noções e práticas obsoletas e agressivas na assistência ao parto vaginal no setor público, e, no setor privado, aderem à concepção misógina de que o parto vaginal é primitivo, inconveniente, insuportavelmente doloroso, repulsivo em seus aspectos mais corporais, e danoso à saúde sexual da mulher - portanto deveria ser "prevenido" sempre que possível. Insistir em ter um parto espontâneo, para aquelas mulheres de classe média que podem evitá-lo, é motivo para estranhamento, e, não raro, para aberta hostilidade por parte dos serviços ${ }^{3}$. O filme mostra as inúmeras mulheres que queriam um parto fisiológico, mas que se sentiram coagidas a fazer uma cesárea sob ameaça de abandono da assistência, ou de sequelas para o bebê (às vezes mediante fraude, como imagens de circulares de cordão no ultrassom forjadas para induzir à cesárea).

Como mostra o Renascimento, ao contrário da crença prevalente no Brasil, o parto espontâneo é hoje considerado um momento privilegiado de promoção da saúde física e emocional, da mãe e do bebê, não apenas a curto prazo, mas com repercussões para toda a vida ${ }^{4}$. Segundo os diretores, o objetivo do documentário é destacar a importância do parto normal - que, poderia ser feito em até $90 \%$ dos casos, contra $10 \%$ de gestações de maior risco - e do trabalho de parto.

Sabe-se hoje que um parto fisiológico bem- sucedido, cercado de respeito e segurança, pode propiciar, para a mulher, uma experiência existencial extraordinária, levando a um sentimento de competência como mãe e como pessoa, e a lembranças positivas associadas à maternidade, o que facilita a vinculação com o bebê e o início da amamentação. Sem mencionar a diferença de bem-estar físico e emocional por estar livre da dor intensa resultante das feridas cirúrgicas pós-parto, sejam resultantes de cesárea ou de episiotomia 5 . Além disso, sabe-se que o parto vaginal propicia uma colonização saudável do microbioma do recém-nascido, levando a um risco diminuído de obesidade, diabetes, asma, alergias e outras doenças crônicas no decorrer da vida. Os nascidos de cesárea, por sua vez, tem seu microbioma inicialmente colonizado por bactérias hospitalares, o que aumenta seus riscos ao longo da vida ${ }^{4}$. A diferença de prognóstico quanto às enfermidades crônicas não transmissíveis relacionada à via de parto, hipótese trazida pelas ciências básicas e confirmada em estudos epidemiológicos, deve ser uma tema crucial para a Saúde Coletiva nos próximos anos.

O Renascimento corajosamente aborda o tema difícil dos conflitos de interesse, seu papel na epidemia de cesárea, e suas repercussões na saúde materna e neonatal. "A gente tem muito mais internações em UTIs nas vésperas de grandes feriados" diz o pediatra Ricardo Chaves. Ele conta que muitas cesáreas são feitas por conveniência médica, em prejuízo dos bebês, o que permite, ao profissional, voltar para o consultório, pois as cirurgias são agendadas com antecedência e duram de 15 a vinte minutos, em 
vez de passar até 12 horas acompanhando um trabalho de parto.

Pode-se dizer, com razão, que o filme aborda, sobretudo, a realidade do setor privado. Estudos mostram que, na cultura brasileira, as usuárias do SUS não tem reconhecido seu direito à autonomia, devendo se subordinar ao julgamento médico acerca do que seria melhor para a gestante e seu bebê, enquanto as mulheres do setor privado, além de serem pagantes, são consideradas "diferenciadas", mais escolarizadas, portanto moralmente mais capacitadas, e teriam, assim, direito à escolha sobre as intervenções ${ }^{6}$. Então, o que um filme sobre "direito à escolha" no parto tem a ver com o SUS? Tudo, se pensarmos a assistência à saúde considerando os princípios da equidade, do controle social, da integralidade, e da humanização ${ }^{7}$.

Quanto à equidade, o filme deixa bem claro: apesar da crença dominante na preferência pela cesárea, o que as mulheres querem é ficar livres de maus-tratos, de abandono, de negligência, de solidão, de ataques à sua integridade física e sexual. Enquanto o parto chamado "normal" for assistido de forma tão agressiva e privada de direitos, a cesárea aparecerá com alternativa menos aflitiva, dolorosa e abandonada. Será uma escolha entre o ruim e o pior, e por isso a busca de tantas mulheres pelo setor privado. Como dizem os movimentos sociais: "Chega de parto violento para vender cesárea"7.

Pode-se dizer também que o parto espontâneo e humanizado, acompanhado por profissionais experientes na assistência ao parto fisiológico, tem se tornado um sonho de consumo, um privilégio das mulheres mais ricas e escolarizadas. Porém em alguns poucos locais, as mulheres do topo da hierarquia social procuram o SUS justamente pelo fato de ser mais próximo deste modelo que o setor privado. Quem quiser saber detalhes, veja, por exemplo, o ótimo vídeo sobre o Hospital Sofia Feldman e seu Centro de Parto Normal (CPN).

Precisamos multiplicar o SUS que dá certo - O que exige coragem e ousadia por parte dos gestores para mudar o modelo agressivo e obsoleto que impera no SUS, apostando na implementação de CPNs e na contratação de obstetrizes e enfermeiras obstetras para o cuidado de gestantes e parturientes saudáveis. Queremos equipes interdisciplinares e integradas ao sistema, com acesso automático e sem hostilidades aos níveis de complexidade necessários em caso de transferência, como em países desenvolvidos. Queremos que o SUS se diferencie do setor privado, que aderiu sem disfarces ao modelo da cesárea obrigatória.

Em termos do controle social, a participação do movimento nas instâncias do SUS tem sido de grande ajuda: por exemplo, em São Paulo, a Conferência Municipal aprovou a construção de cinco centros de parto normal, uma por região do município, o que pode fazer toda a diferença. A ouvidoria da Rede Cegonha tem oferecido um manancial de informação sobre as enormes distorções e sobre o que é preciso mudar, ouvindo diretamente as usuárias do SUS.

Quanto à integralidade, como o filme aborda, o parto é um fenômeno biopsicossocial, e espiritual, e a sua redução às dimensões biológicas não apenas empobrece e entristece a experiência, mas também, evidentemente, reduz a sua segurança e sua efetividade. O modelo do parto fisiológico, facilitado por um cuidado acolhedor, seguro e amigável à mulher, ao bebê e à família, propicia uma transição gravidez-puerpério, e fetalneonatal mais fisiológica, saudável e satisfatória, reservando o uso de medicamentos e de cirurgia para sua utilização apropriada e seletiva, promovendo, assim, a saúde das gerações futuras.

Não custa lembrar que as propostas de humanização do parto inspiraram e anteciparam as propostas do SUS em, pelo menos, uma década, e que a Rede pela Humanização do Parto e Nascimento (REHUNA), em 2013, completa vinte anos de influência nos movimentos sociais e em políticas públicas. E que está bem representada no filme - em personagens, como em ideário.

Simone Grilo Diniz

Departamento de Saúde Materno-infantil, Faculdade de Saúde Pública, Universidade de São Paulo.

Av. Dr. Arnaldo, 715, sala 205. São Paulo, SP, Brasil. 01246-904.sidiniz@usp.br

Palavras-chave: Parto. Humanização. SUS. Direitos das mulheres. Direitos dos pacientes. Ciberativismo.

Keywords: Childbirth. Humanisation. Brazilian National Health System (SUS), Women's rights. Patients'rights. Cyberactivism.

Palabras clave: Parto. Humanización. Sistema Único de Salud (SUS). Derechos de las mujeres. Derechos de los pacientes. Ciberactivismo. 
NOTAS BREVES

\section{Referências}

1. Scaggianti V, Schub S. Parto de Sabrina Ferigato, nascimento de Lucas. Fotografia e edição: Além d'Olhar. [acesso 2014 Fev 23]. Disponível em: http://www.youtube.com/watch?v=qiof5vYkPws

2. Zorzam B, Moreiras Sena L, Franzon AC, Brum K, Rapchan A. Violência obstétrica - a voz das brasileiras [acesso 2014 Fev 23]. Disponível em: http://www.youtube.com/watch?v=egOuvonF25M

3. Salgado Ho, Niy Dy, Diniz CSG. Groggy and with tied hands: the first contact with the newborn according to women that had an unwanted C-section. J Hum Growth Dev. 2013; 23(2):190-97.

4. Neu J, Rushing J. Cesarean versus vaginal delivery: long-term infant outcomes and the hygiene hypothesis. Clin Perinatol. 2011; 38:321-31.

5. Fenwick J, Hauck Y, Schmeid V, Dhaliwal S, Butt J. Association between mode of birth and selfreported maternal physical and psychological health problems at 10 weeks postpartum. Int J Childbirth. 2012; 2(11):115-25.

6. Martinho RL. Humanização do parto: análise da teoria e implantação do programa em Salvador [tese]. Salvador: Instituto de Saúde Coletiva, Universidade Federal da Bahia; 2011.

7. Diniz SG, D'Oliveira AFPL, Lansky S. Equity and women's health services for contraception, abortion and childbirth in Brazil. Reprod. Health Matters.

2012; 20:94-101. 